cluding, $F$. A high power should be used, and the prisin should be adjusted for the minimum deviation of the central ray of this portion.

The tube spectroscope should be used in a similar manner for the other part, including $F$. Intensities referred to $F$ to be most carefully noted.

Care to be taken that observers are not interrupted for two hours after totality.

Instruments to be returned to Galle, and shipped in $P$. and $O$. steamer, consigned to J. Browning, I I , Minories, London, E.C. All observations, photographic plates, drawings, \&c., to be sent to Mr. Lockyer within a week of the eclipse. Observers to keep exact duplicates in case of loss.

The following resolutions were passed by the Government of India in the Home Department-under date 27th July and 2ist October :-

"Colonel Tennant has already been authorised demiofficially to provide the astronomical instruments and photographic apparatus that he will require for his observations, and the Governor-General in Council understands that he is now in communication with Prof. Airy and Mr. Huggins on the subject. The cost of these appliances has been included in the estimate appended to Colonel Tennant's memorandum.

"In addition to these instruments, Colonel Tennant will require the aid of qualified observers, and it has been ascertained that the Superintendent of the Great Trigonometrical Survey is prepared to place the services of $\mathrm{Mr}$. Hennessey and Captain Herschel, belonging to his department, temporarily at the disposal of Colonel Tennant for this purpose without prejudice to their proper duties. The Governor-General in Council approves of this arrangement, and is pleased to direct that the Survey officers above-named shall suffer no loss of their allowances while so employed, and that they shall have their travelling expenses paid out of the allotment of Rs. 15,000 sanctioned on account of the Eclipse observations. Colonel Tennant will arrange with Major Montgomerie beforehand when the officers in question should join them.

"The Governor-General in Council is further pleased to direct that Colonel Tennant shall receive from the Surveyor General's Department all the aid that he may require as regards photographic assistants, chemicals, \&c.

"Lastly, the Governor General in Council is pleased to direct that the report of the result of Colonel Tennant's observations, and his accounts, shall be submitted by him to this department."

"From the correspondence received with the above despatch, the Governor General in Council has learnt that an expedition is being sent out from England under instructions from the Eclipse Committee of the British Association, and he is desirous that the Government of Madras will afford the expedition such assistance as it may require in the furtherance of its operations. Such assistance will probably consist in the provision, on a moderate scale, for three or four persons, at each place selected, of tents, means of subsistence, and locomotion, and in the erection of temporary observatories of a simple form. It may also be desirable to depute one or two persons to each party from the Public Works Department to assist the observers.

"Information has also been received that the French Government has deputed M. Janssen to visit India with the same object, and the Governor General in Council desires that the Government of Madras will afford every facility and assistance to that gentleman also.

"The Financial Department will be moved to sanction any reasonable expenditure that may be necessary to enable the Government of Madras to give effect to these instructions,"

\section{ARCTIC EXPLORATIONS}

A SHORT paper of mine on the above subject appeared in NATURE of the 7 th December, in which I stated some reasons for my belief that Smith Sound possesses no apparent advantages over Spitzbergen as a route by which to reach a very high northern latitude or the Pole itself. In fact I think the advantages are all the other way; and I shall endeavour to show one or two more reasons than I have already given for this belief.

Kane's and Hayes' ships were stopped by ice in Smith Sound before they reached lat. $79^{\circ}$, and this, I think, can readily be accounted for by the peculiar contour of the coast-line, as may be seen by the accompanying rough outline, taken from a copy of Dr. Hayes' chart in the Royal Geographical Society's Map-room.

The width of Kennedy Channel (a continuation of Smith Sound) is at $80^{\circ}$ north lat. about 40 miles, but between latitudes $79^{\circ}$ and $80^{\circ}$, Smith Sound expands to a width of something like 100 miles, this expansion being chiefly formed by a large bay on the east side. The south point of this bay, which I have marked $A$ in the accompanying chart, runs far to the west in lat. $78^{\circ} 30^{\prime}$ (thus changing the direction of the Sound from nearly true north and south to N.E. and S.W.), and approaching within 30 miles of the west shore at the point $B$.

If there is, as I believe, a set or drift of current southward, the ice will first be pressed with great force-as Kane found to his cost-against that side of the bay of which $A$ is the south point, and then it will be driven across to the west shore somewhere near $B$ at the narrowest part of the Sound in a closely-packed and continuous stream of heavy floes hitherto found impene. trable.

Should this idea be correct, and there is something more than theory to support it, this obstruction will be a constant and not an occasional one as long as there is a supply of ice to the north.

If there is a large opening extending far to the west at the place marked $C$, we have another probable opposing element; for if the set of current runs eastward through it, we shall have an important addition to the Smith Sound supply of ice, in making the barrier of the "pack" more formidable. The opinion I express as to the direction of the currents is not wholly hypothetical, for we have proofs of an almost constant current (it is sometimes reversed by strong winds) setting southward down Baffin's Bay and Davis Strait ; and this current can only be fed by Lancaster and Smith Sounds and other openings to the west and north.

The only hope of an "easy" passage up Smith Sound to a higher latitude than $78^{\circ} 40^{\prime}$ is the existence of Kane's "great open Polar Sea," for if such sea does exist, there would be no ice to the northward to keep up the supply of this commodity in Smith Sound, which would in the summer months be cleared of its winter covering by the southerly drift I have already mentioned, and the Sound would, and probably will be, consequently free from ice in August. But this is opposed to both Kane's and Hayes' experience, whatever their expressed opinions about the large open sea may have been.

That Kane's man Morton saw a very considerable extent of open water is not to be doubted, also that it may be quite true that he saw no ice to the northward, although he put down a point of land (whether correctly or not it is difficult to say) seventy miles distant in that direction. Every one, however, must be aware-for it is not necessary to have been in the Arctic seas to acquire such knowledge--that when the temperature of the air is lower than that of the water, a vapour or haze is formed by condensation, which, although by no means dense when looking through a small extent of it, becomes so much so when the observer has to look through eight or ten miles of it, that any low object, such as floe ice, would be quite in-s 
visible at either of these distances, and the haze itself would give the appearance of a distant water horizon.*

The opinion that this open sea was of limited extent is, I think, further confirmed by what Mr. Morton states as a proof (as he thought) of its being "boundless" or very large. Morton says "that he remained for three days watching the open sea rolling in waves at his feet, and, although there was a strong breeze or gale blowing from the north all the time, not a single piece of ice" floated past to the southward. $\downarrow$

My interpretation of the above fact is quite the opposite to that of Morton, for I believe there was a barrier of fixed ice at no great distance to the north, hid from his view by the cause I have named, which prevented any ice driving south at the season of the year when Morton was there, I think in June.

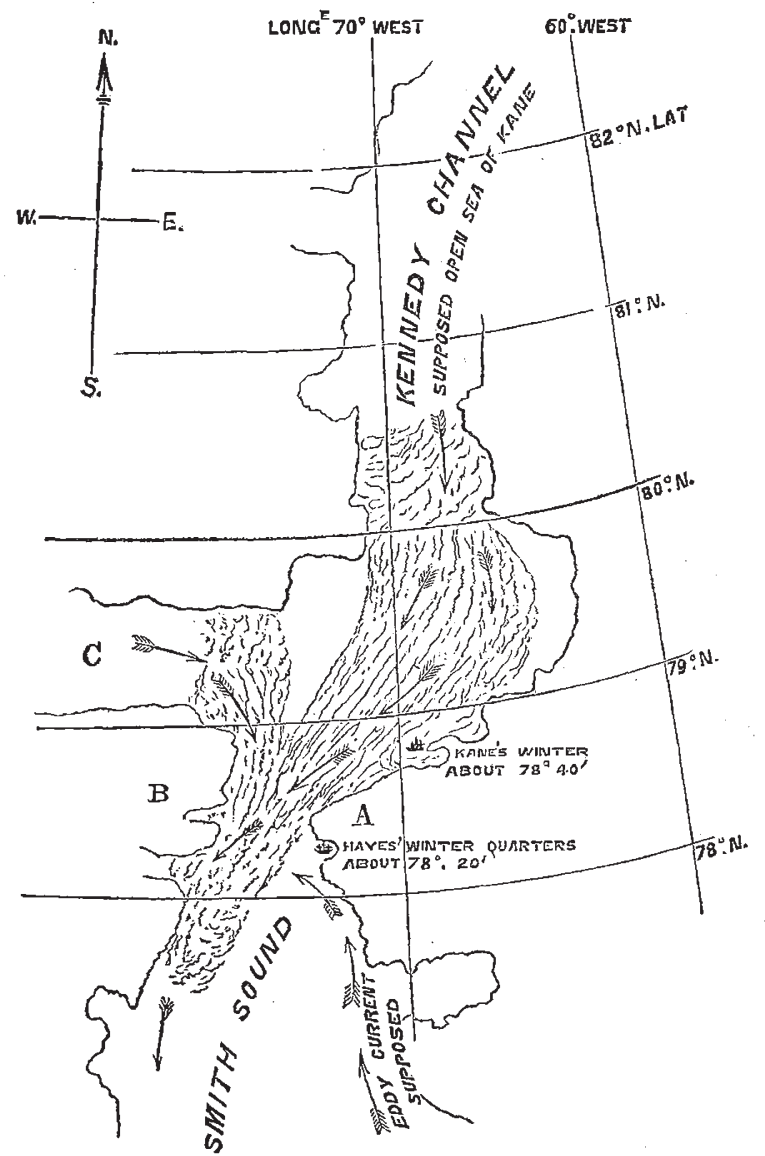

I offer these opinions with much diffidence, for we have been recently told that all great Arctic authorities now agree as to the Smith Sound route being the best. When the subject was brought prominently to notice in 1865 , the "great authorities" did not agree, there being about as many opinions on one side as on the other.

At that time, without the slightest pretence to being an "authority" in the matter, I looked rather closely into the figures on which the facts favourable to the Smith Sound route were founded, and finding these figures in several important instances erroneous, the facts themselves lost much of their value.

JOHN RAE

* I use the term "water horizon" in opposition to "ice horizon," which exhibits a bright line easily recognisable by those who have once seen it.

$\dagger$ As I quote from memory, I give to the best of my belief Morton's meaning, if not his words.

\section{THE TYPHOON OF and SEPTEMBER, I87I}

THE Typhoon in China of the and September last, detailed accounts of which reached England by the last mail, and which included in its area of most active violence the island and vicinity of Hong Kong, affords to those interested in such natural phenomena an opportunity of observing their varied characteristics, that may possibly never occur again. The great centre of its efforts having been in a situation where elaborate observations could be taken regarding it both at sea and land, a vast amount of information has been collected on the subject, which throws more light upon these singular "freaks of nature" than has ever before been arrived at.

In treating on the subject, I shall in the first place point out the course which-after careful investigation -I believe the typhoon to have followed, and afterwards I shall state the evidences that I adduce in support of the theory which I have adopted. Before commencing, however, it may be as well briefly to illus. trate the plan engraved. The names Formosa, Siam, Onward, Mikado, Woodbine, and Anna Henderson are those of six vessels which were on their way to and within a short distance of Hong Kong during the typhoon, and extracts from whose shipping reports are now before me. A portion of the continent of China is to the north of the plan. The town of Macao and the islands of Hong Kong, Lantao, and Lema are in their respective positions.

The course which was taken by the typhoon was nearly allied to a parabolic curve. I have not attempted to trace its source farther eastward than the position indicated by $22^{\circ} 30^{\prime} \mathrm{N}$. lat. and $116^{\circ} \mathrm{ro}^{\prime} \mathrm{E}$. long, where it overtook the Formosa (see $a$ in map), or to follow it beyond the point indicated by $21^{\circ}{ }^{\circ} 5^{\prime \prime} \mathrm{N}$. lat. and II $5^{\circ} 45^{\prime}$ E. long., where it struck the Onward (see of in map) on its return from the West. This portion of its course is marked in the plan by a succession of dotted lines. Consequently my observations are confined to the proceedings of the typhoon within these limits. After passing the Formosa, it swept over Hong Kong, crossed the mouth of the Canton River, and continued its headlong career to the town of Macao. Approaching this point, however, it was met by a strong northerly gale, and turned towards the south, but again encountering opposition in the shape of a south-west gale, it returned towards the east, upsetting the Mikado and driving the Onward before it. Throughout its entire course it consisted of a comparatively narrow belt of wind.

So much for the statement of my theorem. Now for its proofs.

I assume that only three conditions are necessary to substantiate my argument :-

I. I must prove that the typhoon reached the various positions which I have indicated in the order actually laid down.

2. That it reached them at successive intervals of time.

3. That its greatest observed efforts were exerted on or in the vicinity of the line adopted by me, and not at any appreciable distance to the right or left of it.

4. That the two opposing gales, which I have described as occasioning the alteration in the course of the typhoon, did actually exist.

The first and second of these four conditions appear to be so intimately connected, that I think I cannot do better than consider them together. The earliest observations of the typhoon were made by the Formosa, which experienced its full force in the situation indicated in the plan between $a$ and $b$. Both positions are accurately determined. The following is an extract from the shipping report: "On September 2, the barometer $29{ }^{\circ} 3$, experienced very heavy typhoon; during the typhoon the ship suffered some damage. At 4 A.M. on 2nd inst., barometer $29^{\circ} 25$, blowing very heavy from east; at 12 noon, the same day, the wind moderated; at 2 P.M. on same made some 